\title{
Andrea Cesalpino
}

\author{
Thaíla Vieira Alves dos Santos*, Bruno Edson-Chaves ${ }^{\sharp}$ \\ * Universidade Estadual de Feira de Santana \\ ${ }^{\dagger}$ Universidade Estadual do Ceará
}

\section{CITAÇÃO}

Santos, T. V. A., Edson-Chaves, B. (2020)

Andrea Cesalpino (1524-1603), dedicou-se à medicina e ao estudo da botânica durante Andrea Cesalpino,

Rev. Ciência Elem., V8(04):063.

doi.org/10.24927/rce2020.063

\section{EDITOR}

José Ferreira Gomes,

Universidade do Porto

\section{EDITOR CONVIDADO}

João Lopes dos Santos

Universidade do Porto

\section{RECEBIDO EM}

20 de novembro de 2020

\section{ACEITE EM}

24 de novembro de 2020

\section{PUBLICADO EM}

15 de dezembro de 2020

\section{COPYRIGHT}

(C) Casa das Ciências 2020.

Este artigo é de acesso livre, distribuído sob licença Creative Commons com a designação CC-BY-NC-SA 4.0, que permite a utilização e a partilha para fins não comerciais, desde que citado o autor e a fonte original do artigo.

rce.casadasciencias.org

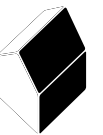
sua vida. Sua obra botânica mais expressiva foi De Plantis (1583), onde descreveu cerca de 1.500 plantas em seus quatro volumes. Seus estudos influenciaram profundamente $o$ estudo da sistemática vegetal que se seguiu. $\mathrm{Na}$ área médica seus estudos sobre fisiologia cardíaca foram precursores do conceito atual de circulação sanguínea fechada.

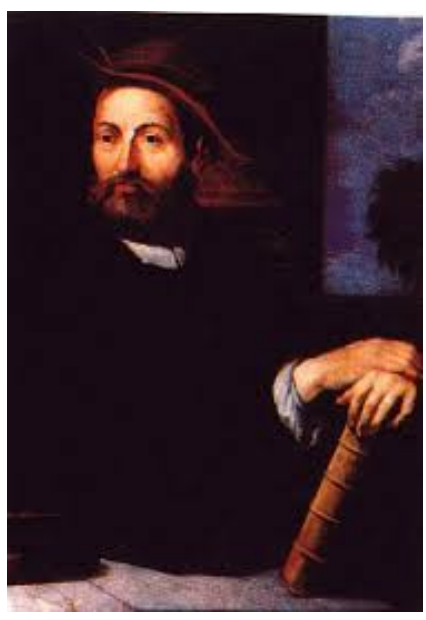

FIGURA 1. Andrea Cesalpino (1524-1603)

Andrea Cesalpino nasceu em Arezzo, Itália, no ano de 1524, filho de Giovanni di Andrea. Estudou medicina em Pisa, onde posteriormente se tornou professor de medicina e diretor do Jardim Botânico na mesma cidade. Viveu em Roma por cerca de onze anos, onde foi médico do Papa Clemente VIII, além de lecionar medicina na Universidade de Sapienza. Foi em Roma também que ele finalizou seus manuscritos sobre arte médica, metais e o apêndice da sua obra botânica De Plantis (FIGURA 2). Ele foi casado com Gherarda di Bernadio Baroncini di S. Geminiano, com quem teve um único filho, morreu em 23 de fevereiro de 1603.

Cesalpino foi o primeiro naturalista que buscou organizar os minerais e os seres vivos em um sistema de classificação, a partir de seus estudos iniciou o período de sistematização dos organismos. Diferentemente dos naturalistas do período descritivo, sua classificação buscou não somente descrever a natureza, mas também produzir um sistema útil para a comunidade, de fácil utilização e memorização. Neste contexto, podemos dizer que o sistema de classificação proposto por ele é definido como um sistema artificial pois agrupava os minerais e as plantas com base em caracteres morfológicos arbitrários. Para os minerais ele os classificou em: terra, sais, substâncias solúveis em óleo, solúveis em água e os que se fun- 
dem na presença de fogo. Seus estudos sobre os seres vivos the colocam entre os primeiros taxonomistas da história.

Conhecido como botânico excepcional, traçou leis e princípios para o estudo das plantas, estabelecendo comparações entre elas e categorizando gêneros, em uma das primeiras tentativas de um sistema de classificação vegetal. Na obra De plantis, considerada o primeiro livro-texto de botânica e publicada em quatro volumes no ano de 1583, ele agrupou inicialmente as plantas pelo seu hábito, entre árvores e ervas, e as classificou com base nos caracteres morfológicos do ovário, frutos e sementes, bem como número de lóculos no ovário, presença ou ausência de bulbo e características da seiva (leitosa ou aquosa). Como resultado, tinha descrito cerca de 1.500 plantas, dividindo-as em 15 classes. Embora Cesalpino tenha sido um expoente estudioso de botânica, ele não estava livre dos equívocos conceituais da sua época, como admitir que fungos surgiam por geração espontânea.

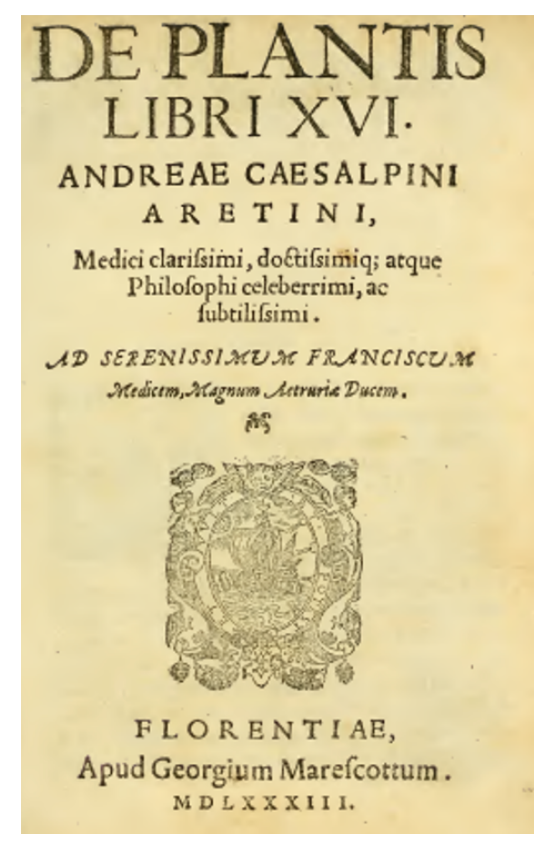

FIGURA 2. Compêndio botânico "De plantis" (As plantas).

Seus estudos na área médica foram amplos, mas suas descobertas mais significativas foram focadas em anatomia e fisiologia cardíaca, ao passo que é considerado como aquele que descobriu a pequena e grande circulação; aliás, seus trabalhos antecedem em 50 anos o uso do termo "circulação" aplicado por William Harvey na teoria da circulação sanguínea fechada. Apesar de reconhecer que o sangue corria nas veias em direção ao coração, Cesalpino não compreendia que o sangue fluía em um único sentido. Mesmo assim suas contribuições foram muito relevantes, fornecendo dados importantes sobre a relação do coração, veias e artérias, que futuramente alicerçaram a teoria de William Harvey.

\section{REFERÊNCIAS}

${ }^{1}$ ARAÚJO, M. F. F. et al., História da Biologia. 2a ed. Natal:EdUFRN, 214p. 2012.

${ }^{2}$ BRESINSKY, A. et al., Tratado de Botânica de Strassburguer, 36ํe ed. Porto Alegre: Atmed. 1166p. 2012.

${ }^{3}$ BRUCE W. F., Profiles in Cardiology: Andrea Cesalpino. Clin. Cardiol. 19, 969-970. 1996.

${ }^{4}$ CAPPARONI, P., Profili bio-bibliografici di medici e naturalisti celebri italiani dal sec. XV al sec. XVIII. Istituto naz. medico Farmacologico. 1925.

${ }^{5}$ FERNANDES, A., Compêndio botânico. Fortaleza: EdUFC, 142p. 1996. 


\section{REVISTA DE CIÊNCIA ELEMENTAR}

\footnotetext{
${ }^{6}$ JUDD, W. S. et al., Sistemática vegetal: um enfoque filogenético, 3ae ed. Porto Alegre: Atmed. 632p. 2009.

${ }^{7}$ KUSUKAWA, S., The role of images in the development of Renaissance natural history. Archives of Natural History 38(2):189-213.DOI: 10.3366/anh.2011.0028. 2011.

${ }^{8}$ MARTINS-DA-SILVA, R. C. V. et al., Noções Morfológicas e Taxonômicas para Identificação Botânica. Brasília, DF: Embrapa, 111p. 2014.

${ }_{9}^{9}$ MOGGI, G., L'Erbario di Andrea Cesalpino. in: Rafaelli M. The Museum of History of the University of Florence, V. II. 2009.

${ }^{10}$ MORGAN A.G., A letter of Andrea Cesalpino. Archives of Natural History, 14(2):169-173. 1987.
} 